\title{
Dislocation, not dissociation: The neuroanatomical argument against visual experience driving motor action
}

Benjamin Kozuch $^{1}$

Forthcoming in Mind and Language.

\begin{abstract}
Common sense suggests that visual consciousness is essential to skilled motor action, but Andy Clark - inspired by Milner and Goodale's dual visual systems theory - has appealed to a wide range of experimental dissociations to argue that such an assumption is false. Critics of Clark's argument (e.g., Wallhagen, Mole) contend that the content driving motor action is actually within subjects' experience, just not easily discovered. In this paper, I argue that even if such content exists, it cannot be guiding motor action, since a review of current visual neuroscience indicates that the visual brain areas producing conscious representations are distinct from those driving motor action.
\end{abstract}

\section{1: Introduction}

At first glance, it might just seem obvious that the rich information found in visual experience is indispensable to fine-tuned motor actions, things like carrying a brimming cup of coffee or catching a ball. Consider what it is like to descend a rocky trail. Picking your way through the obstacles, your visual experience seems to contain metrically precise representations of things like the pitch of the ground and the position of rocks. Because these representations are detailed, they look ideal for guiding the fine-tuned motor actions needed to safely cross the ever-changing terrain. It is observations like this one that brought some philosophers (O'Shaughnessy 1992; Peacocke 1992; Cussins 1998; Grush 1998) to hypothesize that visual experience is what guides skilled motor action, a view Andy Clark (2001) dubbed the thesis of experience-based control, hereafter EBC. ${ }^{2}$

The author would like to thank Uriah Kriegel, Brian Fiala, and Shaun Nichols (as well as the editors and referees of Mind and Language) for insightful comments on earlier drafts of this paper.

Address for correspondence: University of Arizona Philosophy Department, 213 Social Sciences, P. O. Box 210027, Tucson, AZ 85721-0027, USA.

Email: bigben@email.arizona.edu

${ }^{2}$ When Clark originally presented the hypothesis of EBC, it was a conjunction of three claims: (1) Visual experience 'presents the world to the subject in a richly textured way, a way that presents fine detail'; (2) 
Clark has argued against EBC by appealing to a large body of experiments in which the content guiding motor action seems missing from visual experience (2001, 2007, 2009; cf. Milner \& Goodale 1995/2006). There is the well-known case of patient DF, whose brain lesion seems to affect only her ability to visually experience an object's shape, but not her ability to grasp it (Milner \& Goodale 1995/2006, Chap. 5). Then there are the numerous experiments in which subjects' motor actions appear unaffected by consciously experienced visual illusions (e.g., Aglioti, DeSouza \& Goodale 1995). The sum of these and other data is a formidable case against EBC.

If Clark is right, and visual experience is only distantly related to motor action, this looks like one more in a string of rebukes recently served to folk psychology, just as in the case of our commonsense understanding of introspection (Nisbett \& Wilson 1977), rationality (Tversky \& Kahneman 1983), and conscious intention (Wegner 2002). The falsity of EBC also stands to extirpate a budding approach to understanding consciousness, so-called enactive theories (O’Regan \& Noë 2001; Noë 2005), since such theories are predicated on a tight link between consciousness and motor action (Clark 2006; Brogaard 2011a). Much appears at stake, then, when it comes to EBC.

Key to Clark's argument against EBC is it really being the case that, in the experiments that he appeals to, the visual content driving motor action is absent from subjects' visual experience. It has been argued, however, that such content is not absent, just unreportable or otherwise hard to discover (Wallhagen 2007; Mole 2009). Not surprisingly, it has proven difficult to rule out this hard-to-discover content, and I argue below that Clark's attempts (2007; 2009) to do so are unsuccessful.

Nonetheless, there merely being such content in subjects' experiences is not enough to help $\mathrm{EBC}$; for this, we need reason to think that this content is actually driving motor action. In this paper, I argue that a review of the relevant neuroscience reveals this probably is not the case. More specifically, there appear to be no representations in the visual system that both are conscious and feed directly into motor action, something that we would expect if EBC were true. The good news here: To pass verdict on EBC, we need not first resolve difficult issues concerning the possibility of conscious but unreportable content.

The rest of the paper is as follows: In Sect. 2, I examine the thesis of EBC, and review the lesion and psychophysical evidence marshaled against it. In Sect. 3, I look at how advocates of EBC have undermined this evidence, and argue that Clark's main response to this undermining is unsuccessful. In Sect. 4, I review the neuroscientific data relevant to $\mathrm{EBC}$, arguing that they

visual experience 'is, in virtue of this richness, especially apt for...the control and guidance of fine-tuned, real-world activity'; and (3) visual experience is in fact 'typically utilized' in such control and guidance (2001:496). Since Clark introduced the hypothesis of EBC, the debate has largely narrowed to just the third claim, this also being what we will be concerned with here. 
show there to be no areas in the visual system producing representations both conscious and directly used in motor action. In Sect. 5, I consider objections.

\section{2: The dissociation argument}

EBC hypothesizes a tight link between visual experience and skilled motor action, but what is the nature of this connection? In the philosophical debates concerning the relationship between visual experience and motor action, there is no one formulation of EBC universally and explicitly adopted. ${ }^{3}$ Nonetheless, we can base a formulation around the key features it is usually taken to have (see, e.g., Clark 2007; Wallhagen 2007; Briscoe 2009). This looks as follows:

EBC: The content of visual consciousness is what is typically used to directly guide visually based motor actions

A few remarks: First, there are two ways to understand EBC. It can be regarded as a philosophical hypothesis, one based on the idea that the rich, detailed kind of content found in visual experience seems well-suited to guiding visuomotor action. But EBC is also often regarded as an expression of the commonsense view of the relation between vision and action (the one that cognitive science looks in danger of overturning). Hold this thought.

Now notice that, since EBC says that the guidance of motor action by visual experience is both typical and direct, we can think of EBC as having both a typicality clause and a directness clause. The question now arises as to whether EBC qua the commonsense view requires typicality and/or directness. Another issue concerns how we are to say, in practice, what counts as being 'direct' or 'typical' guidance. These matters are addressed at more advantageous times.

Finally, there is the question of what is meant by 'consciousness,' this being a term variously understood (Chalmers 1995). Listening to participants in the debate, a natural interpretation emerges according to which $\mathrm{EBC}$ is a thesis concerning phenomenal consciousness (Nagel 1974; Block 1995; Chalmers 1995). A mental state is phenomenally conscious if and only if there is 'something it is like' to have that mental state, if it is experiential. We can understand $\mathrm{EBC}$, then, as saying that it is the content of visual experience that guides motor action.

There appears to be a significant empirical case against EBC. This section surveys the relevant evidence, and looks at how it has been used to cast doubt on EBC. First, though, we look at the inspiration for empirical arguments against $\mathrm{EBC}$, dual visual systems theory.

\footnotetext{
${ }^{3}$ Here, I am taking philosophers such as Mole $(2009$; 2013) and $\mathrm{Wu}(2013$, forthcoming) to be a part of the debate over EBC, even though they often only explicitly engage with what they call the 'zombie action hypothesis.' The zombie action hypothesis is - for all intents and purposes - just the denial of EBC. (For discussion, see Wu 2013, p. 1-2.)
} 


\subsection{Dual visual systems theory}

When light stimulates receptors in the retina, the receptors mostly send their signals to the lateral geniculate nucleus of the thalamus (a subcortical structure often known as the sensory 'relay station of the brain'), and from there on to the primary visual cortex. Upon leaving the primary visual cortex, the visual system divides into two semi-autonomous pathways known as the ventral and dorsal streams, the first projecting to the temporal cortex, the second to the parietal cortex (Morel \& Bullier 1990; Young 1992; but see Prinz 2012, Chap. 6). The discovery of multiple pathways in the visual system gave rise to a series of dual visual systems theories, which attribute different functions to the distinct processing streams (Schneider 1969; Ungerleider and Mishkin 1982; Ungerleider \& Haxby 1994). The currently ascendant dual visual systems theory is that of Milner and Goodale (1995/2006; cf. Jacob and Jeannerod 2003), who hypothesize the ventral stream to be associated with perception and goal-oriented cognition, and the dorsal stream to provide the information used in visuomotor action (but see Pisella et al. 2006, 2009; Schenk \& McIntosh 2010). Milner and Goodale's theory also involves a less widely accepted claim, which is that conscious visual perception is confined to the ventral stream.

This last claim is of course important to evaluating EBC. Were it correct, it looks like EBC's directness clause is unfulfilled: Any influences that visual experience had upon motor action (however typical) would be mediated by whatever areas actually directly guide visuomotor action. And so one promising way to build a case against EBC is to argue that the areas in the brain where conscious visual representations are produced are anatomically distinct from those where visuomotor representations are produced. Let us call this the neuroanatomical argument against EBC.

The most well-developed argument against EBC, due to Clark (2001, 2007, 2009; see also Milner \& Goodale 1995/2006; Koch \& Crick 2001), is not best characterized as a neuroanatomical argument. ${ }^{4}$ Instead, Clark's approach is to describe a number of instances in which skilled visuomotor action seems to come apart from visual experience, and argue that the best explanation of these dissociations is that visual experience does not typically or directly guide motor action. Call this the dissociation argument. ${ }^{5}$ It is to this that we now turn. Later, I develop a version of the neuroanatomical argument.

\footnotetext{
${ }^{4}$ The work of Milner and Goodale can be viewed as including a neuroanatomical argument against EBC (see esp. 1995/2006; 2008), one that I aim to improve upon below.

${ }^{5}$ What I here refer to as the 'dissociation argument' should not be confused with the double dissociation arguments offered on behalf of dual visual systems theory (Milner and Goodale 1995/2006; Jacob \& Jeannerod 2003). These arguments use some of the same data discussed below to argue for a related conclusion, which is that the systems in charge of visually guided behavior are functionally distinct from those carrying out perceptual tasks (such as object identification).
} 


\subsection{The dissociation argument against $E B C$}

Clark has enlisted two lines of evidence in building his dissociation argument: The first is the effects of lesions to the visual system, the second is psychophysical experiments involving visual illusions. We examine each in turn.

Lesions to the ventral and dorsal streams provide striking examples of dissociations between visual experience and visuomotor action. One disorder thought to present particularly strong evidence against EBC is visual form agnosia, an inability to perceive object shape (Heider 2000). There are a few recorded cases of visual form agnosia (Benson \& Greenberg 1969; Efron 1969; Campion 1987), but the one most thoroughly studied is that of DF, a Scottish woman with ventral stream damage resulting from carbon monoxide poisoning. DF's lesion appears to have caused deficits in her conscious perception of things like the shape and position of an object, but left her ability to perform visuomotor actions unaffected. In what is called the 'posting task,' a subject is asked to fit an envelope into a narrow slot of varying orientations. DF can perform this task with facility, but at the same time is unable to report the orientation of the slot (Goodale et al. 1991; Milner et al. 1991). She can also easily step over obstacles the height of which she cannot estimate (Patla \& Goodale 1996). Examples of DF displaying similar dissociations abound (Milner \& Goodale 1995/2006:128-33). Dorsal lesions, on the other hand, bring about an opposite pattern of deficits (Perenin \& Vighetto 1983, 1988). Some subjects with dorsal damage, for instance, can discriminate the orientation of lines correctly, but are unable to perform the kind of motor actions involved in the posting task. All in all, the results of lesions to the ventral and dorsal streams seem to act as compelling evidence against EBC.

Also counting against $\mathrm{EBC}$ are dissociations revealed in experiments involving visual illusions. In the Titchener illusion, two interior circles are surrounded by annuli of either smaller or larger sized circles, which causes subjects to misjudge the relative size of the interior circles (e.g., judge two circles of the same size to be different). Aglioti and colleagues (1995) constructed an interactive Titchener illusion using wooden disks placed on a table, asking subjects to both pick up and judge the size of the two central disks. Though subjects reported the disks to be differently sized, their grip aperture was largely unaffected by the illusion (see also Haffenden \& Goodale 1998). While these particular experiments are somewhat controversial (Franz et al. 2001), numerous similar dissociations between visual consciousness and visuomotor action have been found in experiments utilizing the Ponzo illusion (Brenner \& Smeets 1996; Ellis, Flanagan \& Lederman 1999), the Roelofs effect (Bridgeman, Peery \& Anand 1997), the hollow face illusion (Kroliczak 2005), and various forms of induced illusory motion (Bridgeman et al. 1979; Bridgeman, Kirsch \& Sperling 1981; Wong \& Mack 1981; Goodale, Pelisson \& Prablanc 1986). 
It is natural to think that the best explanation of these numerous dissociations is that visual experience is not what typically and directly guides visuomotor actions. Such, at least, is the conclusion of the dissociation argument.

This conclusion should be clarified in two ways. First, the dissociation argument is meant only to rule out visual experience from being what typically plays a direct role in guiding motor action. Thus it is often granted by the critic of EBC (Milner \& Goodale 1995/2006; Goodale 1998; Clark 2001, 2007) that visual experience plays indirect roles, such as the selection of objects toward which a motor action is to be performed. Second, the dissociation argument should not necessarily be taken to say that visual experience never plays a direct role. As we will see below, there is evidence that it might do so under certain circumstances, such as when motor actions are delayed (Hu, Eagleson \& Goodale 1999; Hu \& Goodale 2000). But the conclusion of the dissociation argument does say that visual experience fails to play the kind of central and direct role in motor action that would be suggested by untutored intuition, in that 'conscious visual experience is not, despite appearances, in the business of providing the information used to control most daily visuomotor action' (Clark 2007:570).

\section{3: Responses to the dissociation argument}

In the dissociation argument, one argues against $\mathrm{EBC}$ by pointing out instances where the content driving motor action appears missing from, or mismatched with, the content of subjects' experiences. Accordingly, responses on behalf of EBC have consisted of arguments that such content actually is with the experience of subjects, just unreportable or otherwise hard to discover. In this section, I look at these responses, along with Clark's rejoinder. I argue that Clark's rejoinder is inadequate, meaning efforts to undermine the dissociation argument have succeeded.

As just said, the advocate of $\mathrm{EBC}$ responds to the dissociation argument by arguing that there is, within the experience of subjects, content matching the content driving motor action. Wallhagen claims that visual form agnosic DF must experience the form ${ }^{6}$ of an object, since she experiences color and texture, and 'if color and texture are present, then...features such as shapes...must be present as well - minimally, as the boundaries of colored, textured regions' (2007:557; but see Mole 2009:1004-5). DF's inability to report the form of objects is not due to a lack of shape experience, contends Wallhagen, but rather an inability to bring her form experiences under concepts, as would be necessary for report. Similarly, Mole hypothesizes that,

\footnotetext{
${ }^{6}$ Responses to the dissociation argument so far have concentrated on showing that there are form experiences being used in visuomotor action. The term 'form,' as it has been used in these debates, refers to a few related object properties, such as shape, size, and orientation-all those properties that DF appears unable to experience.
} 
in the posting task, DF's visual experience has demonstrative content (like 'this way round') that correctly represents the orientation of the slot (2009; see also 2013). But because this content is conscious 'when (and only when) an action is in play' (2009:1007), it is discoverable only under certain experimental conditions (such as those obtaining in Schenk \& Milner 2006; but see Goodale \& Milner 2010). Wallhagen and Mole resist the visual illusion data in like fashion, arguing that there are multiple, inconsistent contents within the experience of subjects in these experiments, some of which match the content driving motor action (cf. Smeets \& Brenner 2001).

Let us refer to the idea that there is, within the experience of subjects, content matching the content driving motor action as the presence thesis. While Clark argues against the presence thesis in various ways (see also $\mathrm{Wu} 2013$ ), his centerpiece response is the 'argument from agency' (2007, 2009; cf. Clark and Kiverstein 2007). ${ }^{7}$ Start by observing that each of the scenarios Wallhagen and Mole describe involves (phenomenally) conscious content for which it is difficult to find evidence; let us say that such content is arcane. Assuming such content exists, its being arcane is due to the subjects themselves appearing to not know of them. DF, for example, reports that objects 'seem to run into each other,' it being difficult to segment objects within her visual field (Milner, personal correspondence). But we would not expect reports such as these if DF knew of her (purported) form experiences. Similar observations could be made about the visual illusion data, in that the subjects' behavior gives us no reason to suppose that they know of any multiple, inconsistent contents in their experience.

In the argument from agency, it is claimed that arcane content of the sort described cannot be conscious. Borrowing from Evans (1982), Clark argues that we should consider content conscious only when it is of potential use to the agent, 'when [it] is poised...for direct and non-inferential use in the guidance of...rational action' (2009:1465; see also Clark 2007; Clark \& Kiverstein 2007). Let us refer to this as the agency requirement. The thrust of Clark's argument is that the arcane content hypothesized by advocates of EBC does not satisfy the agency requirement, and therefore is not conscious.

There are, however, some difficulties that Clark's argument faces. For one thing, there is reason to doubt that the agency requirement is relevant to the present issue, given the kind of support that Clark provides for it. Consider that the presence thesis is a metaphysical claim, a claim concerning whether or not something exists: The presence thesis hypothesizes there to be certain experiential states (namely, phenomenally conscious states), ones possessed by subjects in the experiments, and whose content matches the content driving motor action. But Clark

\footnotetext{
${ }^{7}$ Since the papers in which Clark develops the argument from agency predate Mole's arguments on behalf of EBC, Clark has not used the argument from agency to rebut Mole's arguments in particular. Nonetheless, the argument from agency has been Clark's main response to the presence thesis in its previous forms (O’Regan \& Noë 2001; Nudds 2007; Wallhagen 2007), so we can guess that he would employ it in the case of Mole's version as well.
} 
appears to justify the agency requirement with nothing but conceptual claims; specifically, descriptive or normative claims concerning how our concepts do or should operate. In various places, Clark seems to argue that arcane states cannot or should not be considered conscious because our commonsense concept of consciousness would not classify them as such, ${ }^{8}$ because having a concept of consciousness that allows them would create irresolvable disputes, ${ }^{9}$ or because the concept of a conscious state not available for rational control of action is incoherent. ${ }^{10}$ It is, however, unclear how conceptual considerations like these help to answer the metaphysical question with which we are concerned; viz., whether subjects really are or are not in the hypothesized experiential states (those whose content matches the content driving motor action). ${ }^{11}$

Nonetheless, even if the agency requirement were relevant to evaluating the presence thesis, it might yet fail to rule out much of the arcane content from being conscious. The agency requirement says, roughly, that some state is conscious only if it is available for rational control of action. Key here is the idea that content need not actually be accessed for use in rational control of action, only accessible, 'at least momentarily poised in a way that makes it apt for use (though it need not actually be used) in...personal level reasoning, planning and...deliberate and goal-driven selection [of] action' (2009:1466). Thus Clark does not rule out the possibility of visually conscious states the content of which the subject fails to report upon (even when prompted), since it is possible 'elements that we don't attend to or notice in our visual experience can be thus poised' (ibid., p. 1465).

Understood this way, the agency requirement is too weak to rule out many of the arcane states from being conscious. Perhaps the form content Wallhagen attributes to DF does not satisfy the agency requirement: If such content cannot, as Wallhagen hypothesizes, be conceptualized by DF, then plausibly it is also inaccessible for use in rational control of action.

\footnotetext{
${ }^{8}$ Writes Clark and Kiverstein: '...the notions of conscious experience and reasoned agency....are deeply intertwined...[such that] there are non-negotiable links between...conscious awareness and the...sweep of deliberate actions and choices available to a reasoning subject' (2007:503; italics mine).

${ }^{9}$ Writes Clark: 'Such a critic, by endorsing the idea of experience as that which is somehow phenomenally present to what I dubbed the "bare agent," places the discursive goalposts in a most inaccessible position' (2007:589).

10 Clark argues that allowing for arcane experiences (like those considered above) 'is to allow experience to occur in...informationally isolated islands within the overall agent-economy,' saying we 'should ask ourselves whether this idea really makes sense' (2007:588). Elsewhere he writes 'can we really make sense of...free-floating experiences, of...isolated islets of experience...not even potentially more widely available...as fodder for a creature's rational choices and considered actions?' (2009:1466).

${ }^{11}$ Perhaps Clark means to use the incoherence of the concept to argue that such states could not occur, but no argument is given for this purported incoherence; moreover, that such a concept would be incoherent seems belied by the ongoing (and apparently substantive) debate over whether phenomenal consciousness occurs in absence of access consciousness (see three paragraphs below).
} 
However, most of the arcane content is better construed as accessible (if not yet accessed). Mole (2009), for example, claims that DF, under certain experimental conditions, can access (and report upon) the hypothesized form experiences (viz., if she is asked to name the shape of an object that she is currently reaching for, as she was in Schenk \& Milner 2006). Mole also goes out of his way to explain how a subject in the Titchener illusion experiment might miss there being multiple, inconsistent contents in her experience, claiming that conflicts in content need not be obvious to the subject if some of the contents are demonstrative; but of course no such explanation would be needed if the contents were inaccessible. Similarly, Wallhagen's hypothesizing of multiple, inconsistent contents appears, at the least, uncommitted to the idea that such contents are inaccessible. In sum, the agency requirement looks too weak to rule out many of the hypothesized arcane contents from being conscious, since most of them look accessible, if not yet accessed.

In response to this, the agency requirement could be strengthened, so that content counts as conscious only if it is actually accessed. Construed this way, the agency requirement may well exclude all of the arcane contents from being conscious, since subjects seem to not know of them. But it is a matter of ongoing debate whether content needs to be accessed before it can become phenomenally conscious (Dennett 1995; Block 2007, 2011; Brown 2011; Cohen \& Dennett 2011) ${ }^{12}$ a debate probably not resolved soon. And so a strengthened agency requirement does no better a job at showing the hypothesized arcane content to be not conscious.

I conclude that the argument from agency makes no significant dent in the presence thesis. Interpreted one way, the agency requirement is too weak to rule out a majority of the arcane content hypothesized by the advocate of EBC; interpreted another way, it becomes controversial. In addition, it is unclear whether the agency requirement is relevant to evaluating the presence thesis, since the presence thesis is a metaphysical claim, and the agency requirement is grounded on conceptual claims.

Now, while the argument from agency is Clark's central argument against the presence thesis, it is not his only argument. ${ }^{13}$ Unfortunately, we cannot consider all his arguments here. Nonetheless, let us assume (as I think is the case) that the cumulative force of Clark's arguments at least fails to refute the presence thesis. If so, there is room for a stronger case to be made against EBC. Building such a case is what I try to do next.

\footnotetext{
${ }^{12}$ See also Block 1995; Kouider, de Gardelle \& Dupoux 2007; de Gardelle, Sackur \& Kouider 2009; and commentary on Block's 2007.

${ }^{13}$ For instance, Clark argues that even if there is arcane content in the experience of subjects, such conscious information may not be in the proper format for use in visuomotor action (2001:505-8; but see Briscoe 2009:19-20). Clark also rebuts Wallhagen's suggestion that we should take DF's visuomotor capabilities to indicate that she has form experience, arguing that if such reasoning were good, 'all manner of assembly line robots and other apparently non-conscious devices...would need to be admitted...to the ranks of the conscious perceivers' (2007:585).
} 


\section{4: The neuroanatomical argument against EBC}

It is frequently thought that, if $\mathrm{EBC}$ is true, then it should be the case that visual experience directly guides visuomotor action. This, at least, is an assumption commonly adopted, ${ }^{14}$ and one that I adopt as well. But let us consider one reason for thinking that EBC contains what I above called a 'directness clause.'

Remember that the thesis of EBC does double duty: It can be taken as a philosophical hypothesis, or as an attempt to express the commonsense view. EBC as a philosophical hypothesis of course contains a directness clause, as a matter of stipulation. But what about EBC as the commonsense view? Without extended investigation, it is difficult to say much with certainty about the folk view on the relation between conscious vision and action. Still, it is reasonable to suppose that the folk view takes conscious vision to be indispensable to fine-tuned motor action. There being this assumption explains why the case of DF was met with such sensation: Her normal visuomotor abilities in absence of normal visual experience appeared to be a thorough debunking of the indispensability assumption. Now, suppose that, whenever conscious visual information influenced motor action, it did so only by first being routed through unconscious visuomotor systems ('zombie systems,' as they are called). It seems that this would, in some sense, make DFs of us all (if you will), in that our visual experience would seem to play no larger role in our motor actions than they do with DF. And so there appears at least prima facie reason to think that $\mathrm{EBC}$ (qua commonsense view) contains a directness clause.

What, however, should serve as a criterion for whether a visual state directly guides a motor action? One way of understanding this would be to say that a visual state directly guides motor action if and only if that visual state's influence on motor action is unmediated by another mental state. ${ }^{15}$ However, all guidance of motor action by vision is probably mediated at least by motor states, making this criterion too restrictive. A better one can be built around a fundamental difference between visual and motor states, which is that the former have a mind-to-world

\footnotetext{
${ }^{14}$ Clark, for example, intends to debunk EBC by arguing that 'conscious processes of seeing, willing, and intending... are at work only at one remove from most cases...of world-engaging action' (2007:571, italics mine). Similarly, it is Wallhagen's intention to defend EBC against the claim that 'conscious visual perception is part and parcel of a cognitive system... [that is] only indirectly associated with systems controlling the detailed execution of selected actions' (2007:546, quoting from Clark 2001:517, italics mine). And Mole (2013:2) and $\mathrm{Wu}$ (2013:1) agree that what is at issue is the frequency with which the 'visual representations that directly control and guide mundane bodily actions are unconscious' (italics mine).

${ }^{15}$ This understanding of directness is extracted from some of the ways in which EBC has been understood. Mole, for example, has thought that vindication of the commonsense view requires not just that visual experience make a 'causal contribution to the guidance of movement,' but rather that 'movement control and conscious experience are the work of one and the same system' (2009:1002).
} 
direction of fit, and the latter a world-to-mind direction of fit (cf. Jacob \& Jeannerod 2003, Chap. 8). ${ }^{16}$ Such a criterion looks as follows:

Visual state S directly guides some motor action $\mathrm{M}$ if and only if:

(a) $\mathrm{S}$ causally influences how $\mathrm{M}$ is carried out, and

(b) S's influence is not mediated by some mental state $\mathrm{S}^{*}$, where $\mathrm{S}^{*}$ has a mind-toworld direction of fit

Notice that this criterion has the intuitive result of seeming to label, as directly guiding motor action, just those visual states sitting on the cusp of where perception meets action. At any rate, this way of understanding directness seems plausible enough to justify our tentatively adopting it.

Now we return to $\mathrm{EBC}$ and the directness clause. In the last section, we saw how the dissociation argument was undermined by the possibility of there being, within the visual experience of subjects, content matching the content driving motor action. But the directness clause can be used to build an argument against EBC not susceptible to this kind of undermining. Consider that, if EBC is true, there should be, somewhere in the visual system, representations that both are conscious, and directly guide motor action; let us refer to these as the conscious, (motorically) efficacious representations. In this section, I argue that a look at contemporary visual neuroscience reveals there to be no such conscious, efficacious representations.

I use an argument from elimination. I start by dividing up the cortical visual system into three general areas: the ventral stream, dorsal stream, and early visual areas (the latter being those cortical areas tributary to both the ventral and dorsal streams). ${ }^{17}$ Then I argue that none of these general areas produce the conscious, efficacious representations needed by EBC. ${ }^{18}$ The

\footnotetext{
${ }^{16}$ A visual state has a mind-to-world direction of fit insofar as it (ideally) conforms to whatever the world is actually like, whereas a motor state has a world-to-mind direction of fit insofar as it is meant to bring about a state of affairs in the world (one in accord with the motor plan).

${ }^{17}$ I am considering (the major components of) the ventral stream to comprise areas V2, V3, V4, LO, IT, STS, and TEO. I am considering the dorsal stream to comprise areas V3a, V7, IPS, SPL, and IPL. (It has been recently argued that the dorsal stream actually consists of two sub-streams, the ventro-dorsal and dorso-dorsal [Gallese 2007], but we can lump them together for present purposes.) I am considering the early visual areas to comprise V1 and MT. By grouping MT (also known as V5) in with early visual areas, I follow the lead of Milner and Goodale, who argue that MT should be considered an early visual area specializing in motion processing (1995/2006:218-19; see also Schenk \& McIntosh 2010:53; and below [Sect. 4.3]).

${ }^{18}$ One might wonder whether this argumentative strategy still works if what Prinz has argued is correct (2012, Chap. 6), and there are too many cross-connections between what are considered the ventral and dorsal visual areas to fruitfully think of them as constituting two distinct streams. All that is required for the present strategy, however, is that there be distinct brain areas, since the strategy is to show that the
} 
conclusion: Even if we were to grant the advocate of EBC that there is, within the experience of subjects, content matching the content driving motor action, this does not help EBC, since any such representations do not feed directly into motor action.

Before beginning, I note that given the incomplete state of neuroscientific knowledge, some data appealed to below are tentative and/or open to interpretation. As such, they are sometimes unable to provide decisive considerations against EBC. Nonetheless, looking at the data as a whole, a picture emerges in which current neuroscience seems to stand in opposition to $\mathrm{EBC}$; and this, I think, gives good reason to believe that $\mathrm{EBC}$ is probably false.

\subsection{The ventral stream does not produce the conscious, efficacious representations}

While the ventral stream probably produces conscious representations, these representations appear to not feed directly into motor action. There are two lines of support for this. The first is the indirect and limited effects that ventral lesions have on visuomotor action. The second is neuroimaging evidence that reveals a lack of correlation between ventral activity and visuomotor action. We look at each in turn.

Damage to the ventral stream produces a variety of deficits in visual consciousness, and so it is likely that the ventral stream produces conscious representations. Subjects with ventral damage, depending on the precise lesion location, might experience a deficit of color perception (Damasio et al. 1980; Zeki 1990), form perception (Heider 2000), face identification (Damasio \& Damasio 1983; Gross \& Sargent 1992), or object recognition (Sacks 1985). There are, however, few reports of visuomotor deficits resulting from ventral lesions, and those that do only manifest in conditions that agents rarely (if ever) encounter outside the laboratory. Unfortunately, studies of ventral lesions infrequently involve testing for visuomotor deficits, likely because ventral patients neither present with nor complain of motor difficulties. There has, however, been more interest in investigating the visuomotor abilities of DF, since her case is thought an important source of support for Milner and Goodale's dual visual systems theory. A closer look at DF's visuomotor abilities reveals a role for the ventral stream in visuomotor action, but one falling far short of vindicating EBC.

As discussed above, DF reports an inability to experience things like the shape, position, and orientation of objects. At the same time, her everyday capacity for visuomotor action appears normal (Goodale \& Milner 2004, Chap. 2). This assessment is supported by numerous studies: Among other things, DF has been shown to be able to pick up objects of various shapes and sizes (Goodale et al. 1994), perform the 'posting task' (Milner \& Goodale 1995/2006), and step efficiently over obstacles of various heights (Patla \& Goodale 1996). However, DF presents with visuomotor deficits in certain situations (see Schenk \& McIntosh 2010). DF is less accurate than

directness clause of EBC is not satisfied by showing that there are no brain areas producing representations both conscious and efficacious. 
controls when tested in paradigms where the light is shut off before the motor action is initiated (Rossetti et al. 2005; Himmelbach \& Karnath 2005), where the motor actions are delayed until five seconds after the target is removed (Milner, Dijkerman \& Carey 1999), or where the motor actions are performed with a patch over one eye (Dijkerman, Milner \& Carey 1996, 1999).

It looks, then, as if visuomotor deficits accompany ventral damage only infrequently, and in what seem rather artificial conditions. And even in circumstances where the ventral stream appears to participate in visuomotor action, arguably it is still be the dorsal stream that directly guides motor action: Himmelbach and colleagues (2009) tested normal subjects in the same delayed action paradigm used to examine DF (discussed just above), using fMRI to measure the subjects' brain activity. The task was found to cause increased activity only in dorsal (and not ventral) areas. All in all, while the results of ventral lesions support the idea that the ventral stream sometimes contributes to motor action, these contributions seem neither direct nor typical. ${ }^{19}$

Reinforcing this conclusion are other fMRI studies in which visuomotor action brings no concomitant increase in ventral stream activity. In (James et al. 2003), fMRI was used to measure activity in DF's visual areas while she performed actions like those involved in the posting task. Only dorsal areas showed increased activity. In another study (Culham et al. 2003), subjects were asked to either reach for and grasp a lever (known as the 'grasparatus'), or simply reach for it. The reaching and grasping condition produced significantly more dorsal activity than the reaching-only condition (presumably because of increased cumulative task demand in the former condition), but the level of ventral activity was the same. Were it the case that the ventral stream produced those representations directly used in motor action, it is likely fMRI studies would reveal correlations between the ventral stream and visuomotor action. But neuroimaging experiments such as these (see also Prado 2005) fail to do so.

There is a further problem here for the advocate of EBC, concerning DF in particular. Most of the arguments in favor of the presence thesis have advocated specifically for the possibility of there being conscious representations of object shape guiding her motor actions. It looks, however, as if DF's ventral stream cannot produce shape representations at all: The locus of DF's damage is in the lateral occipital cortex (LO). A number of experiments have shown LO to have increased activation when subjects are presented with colored or grayscale images of

\footnotetext{
${ }^{19}$ Recently it has been argued (Himmelbach, Boehme \& Karnath 2012) that while DF performs motor actions with facility, she does not actually perform at the level of controls in some of the tasks that Milner and Goodale used to originally examine DF. But even if it turned out that DF has minor visuomotor deficits, this would probably not count as evidence for the ventral stream playing an expanded role in visuomotor action: MRI scans of DF's brain (James et al. 2003; Bridge et al. 2013) have found shrinkage of gray matter in DF's dorsal stream (also due to the carbon monoxide poisoning). And so any minor motor deficits that DF might have uncovered would most likely be the result, not of DF's severe ventral damage, but rather her less serious dorsal damage.
} 
objects rather than scrambled versions (Malach et al. 1995; Kanwisher et al. 1996; Kourtzi \& Kanwisher 2000, 2001). In addition, the increased activation LO shows in response to an object does not vary with changes in object position or size (Grill-Spector et al. 1999; Malach et al. 1998), nor does its response to object silhouettes vary according to whether the silhouette is defined by luminance, texture, or motion (Grill-Spector et al. 1998). Such data seem to indicate that LO plays an important role in the conscious representation of object shape (Milner \& Goodale 1995/2006:210; Fankhauser \& Kwasniewska 2009). Given DF's ventral damage is centered on LO, her ventral stream probably cannot produce any experiences of shape DF might have.

In this subsection, we have seen reasons to think that the ventral stream could not produce the conscious, motorically efficacious representations hypothesized by the defender of EBC. First, lesion and neuroimaging evidence reveal the ventral stream to probably not produce the representations that directly or typically guide visuomotor action. Second, in the case of DF, it is particularly unlikely that her ventral stream could produce conscious shape representations, since the locus of her lesion encompasses the area in the ventral stream where object shape is represented.

\subsection{The dorsal stream does not produce the conscious, efficacious representations}

Unlike the ventral stream, there is no reason to doubt that the dorsal stream produces representations that feed directly into motor action. Producing such representations is thought one of its primary functions (see, e.g., Milner \& Goodale 1995/2006; Jacob \& Jeannerod 2003). But, as I argue now, the motorically efficacious representations that the dorsal stream produces (and perhaps all dorsal representations) are probably not conscious.

In the dorsal stream, the representations feeding directly into motor action are often thought to be produced in the posterior parietal cortex (the terminus of the dorsal stream), in two areas known as the intraparietal sulcus (IPS) and superior parietal lobe (SPL) (Milner \& Goodale $1995 / 2006$, Chap. 2). One reason to think this comes from fMRI studies that reveal correlations between visuomotor action and activity in the IPS and/or SPL (hereafter IPS/SPL). The aforementioned 'grasparatus' study (Culham et al. 2003) provides one such example, since in this experiment increased motor demands produced increased IPS/SPL activity (see also Binkofski et al. 1999; James et al. 2003). Further reason to think this comes from the close association between IPS/SPL damage and optic ataxia. I will explain.

We start by considering the specificity of deficits resulting from IPS/SPL damage. Damage here brings about optic ataxia, defined as a deficit in visuomotor action (in, e.g., the grabbing of an object) in absence of any primary visual or motor deficits (such as blindness, or paralysis of the arm). In so-called pure cases of optic ataxia, where damage is restricted to IPS/SPL, the deficits occur in absence of any other visual deficits (Perenin \& Vighetto 1983, 1988; but see Pisella et al. 2009). Optic ataxia also results only from IPS/SPL damage: Lesions 
outside IPS/SPL do not cause deficits confined to visuomotor action. That the specific deficits constituting optic ataxia result from, and only from, IPS/SPL damage suggests that it constitutes the final stage in visuomotor processing, and is where visual information is transformed into a format suitable for motor action. And so IPS/SPL appears to be where motorically efficacious representations are produced in the dorsal stream. The question, then, is whether such representations are conscious.

In approaching this issue, let us consider a different question: If IPS/SPL representations were conscious, which of the conscious visual representations that compose our visual experience would we expect it to be responsible for? Probably, it would be those conscious visual representations the content of which looks potentially useful for motor action. The kind of information largely important for visuomotor action is information about the direction, distance, shape, and orientation of objects, where these properties are represented in an egocentric (viewer-centered) frame of reference (Milner \& Goodale 2008). Indeed, visual experience appears to contain representations of these types, in that objects in visual experience are typically represented (egocentrically) as having a certain direction, distance, shape, and orientation (cf. Briscoe 2009). Because these conscious representations are candidates for use in visuomotor action, let us say that they are potentially motorically efficacious. Now here is the point that I want to make: If IPS/SPL representations were conscious, we would expect IPS/SPL to produce these conscious, potentially motorically efficacious representations. But this appears not to be the case.

Recall that lesions confined to IPS/SPL produce pure cases of optic ataxia (i.e., optic ataxia occurring without any other visual deficits [and not just primary visual deficits]). A number of pure cases were studied by Perenin and Vighetto (1983, 1988; see also Garcin et al., 1967). While subjects in these experiments suffered from those deficits in reaching and grasping that constitute optic ataxia, ${ }^{20}$ they seemed to have normal experience of object shape: They could easily find a specific shape among distractors, and could deftly recognize faces and other objects, these all being skills probably requiring the conscious perception of object shape. ${ }^{21}$ The optic ataxics could also discriminate the direction and orientation of stimuli, even when presented peripherally and for intervals of less then 200 milliseconds. In addition, they could indicate the

\footnotetext{
${ }^{20} \mathrm{I}$ am omitting from the discussion complications concerning the precise extent of the deficits involved in optic ataxia. For instance, Glover (2003) has argued optic ataxia is a deficit specific to the online guidance of visuomotor actions, it not affecting the accuracy of the initial movement involved. Others (Rossetti et al. 2003; Pisella et al. 2006, 2009) have argued optic ataxia only involves deficits in the performance of visuomotor actions toward peripherally located objects. Interested readers should see the just-cited papers, along with Milner and Goodale's criticisms of these views (1995/2006, Chap. 8; 2008).

${ }^{21}$ That these abilities would require conscious perception of shape is evidenced by the difficulty such tasks present for DF, who relies on cues such as color and texture to identify an object, and the sound of a person's voice to identify him or her (Steeves et al. 2006).
} 
distance and position of objects. It appears, then, that IPS/SPL lesions do not produce deficits in those types of conscious representations that appear potentially motorically efficacious. Indeed, when considering the researchers' failure to find any conscious deficits in optic ataxics, the Perenin and Vighetto studies might allow a further conclusion (if perhaps with less confidence), which is that IPS/SPL lesions do not produce deficits in visual experience at all.

It appears, then, that the dorsal stream probably does not supply the conscious, motorically efficacious representations needed by the advocate of EBC: If it did, we would expect to find conscious representations in those parts of the dorsal stream that produce efficacious representations. But IPS/SPL lesions fail to produce deficits in those types of visual experience that are potentially motorically efficacious; in fact, IPS/SPL lesions appear to produce no deficits in consciousness at all. And so while representations in IPS/SPL are motorically efficacious, they are likely not conscious. ${ }^{22}$

Just above, I argued that those dorsal areas that directly drive motor action do not produce conscious representations. This, however, might very well be true of all dorsal areas (Milner \& Goodale 1995/2006; Brogaard 2011a, 2011b). Subjects with generalized damage to the dorsal stream exhibit Balint syndrome (Balint 1909; see also Holmes 1918; Moreaud 2003), which consists not just of optic ataxia, but also oculomotor disorders such as gaze paralysis (AKA 'sticky fixation'), and problems with fixating or visually pursuing targets. So far, none of these are disorders of consciousness per se. But if the lesion producing Balint syndrome extends into the inferior parietal lobe (IPL), it can produce hemispatial neglect (Driver \& Vuilleumier 2001), an inability to notice objects in the contralesional visual field. Some have thought that hemispatial neglect is a deficit of consciousness (Driver \& Vuilleumier 2001; Vosgerau \& Newen 2008; Briscoe 2009; Prinz 2012, Chap. 3), but others believe it better explained as a mere deficit of attention (e.g., Lamme 2006; Block 2007; Jacob \& Vignemont 2010; Brogaard 2011a, 2011 b; Kozuch 2014). ${ }^{23}$

Let us assume, however, that hemispatial neglect is a deficit of consciousness. Even so, it would not provide evidence for IPL activity being constitutive of the contents of consciousness. Consider that damage to IPL brings about no impairment in any specific type of visual experience: It is not, for example, a disorder specifically of color, motion, or shape experience (these result rather from damage to visual areas V4, MT, and LO, respectively). Hemispatial neglect - if it is a disorder of consciousness - is an inability to experience any of an object's properties (color, motion, form, whatever) in the contralesional visual field. Now, it is certainly

\footnotetext{
${ }^{22}$ One might object here that optic ataxics actually have deficits of consciousness, but they remain undetected because they are deficits in a subtle (demonstrative?) kind of conscious content. This objection (along with some others) are answered in Sect. 5.

${ }^{23}$ Another potential disorder of consciousness resulting from dorsal damage is simultagnosia, an inability to attend to more than one object at a time. The same points I make about hemispatial neglect below also apply to simultagnosia, and so, for sake of economy, I omit further discussion of it.
} 
possible that this pattern of deficits arises because IPL produces some of the representations that are found in visual experience. But the more natural explanation would be that the conscious representations in question are located elsewhere (e.g., V4, MT, and LO), and that IPL activity is merely somehow necessary for these representations becoming conscious. ${ }^{24}$ Thus even if hemispatial neglect were a deficit of consciousness (and not merely attention), this only provides reason to think that IPL is closely connected with visual experience, but not that it produces conscious representations.

Recently, some philosophers have argued that dorsal areas V3A and/or V7 might produce conscious representations. The most developed case for this is due to $\mathrm{Wu}$ (forthcoming; see also Prinz 2012, Chap. 6), who argues that one or both of these areas produce conscious representations of object distance. Wu supports this claim by appealing to an imaging study in which V3A and V7 showed increased activity when subjects were asked to report on the egocentric distance of objects (Committeri et al. 2004), and by describing a case where damage to these areas produced deficits in the ability to estimate object distance (Berryhill \& Olson 2009). Notably, experience of object distance was among the types of visual experience that we classified above as potentially motorically efficacious. These data might be the beginning of a promising line of argument to be made on behalf of EBC.

There are, however, two further things needed before this is helpful to EBC. The first is reason to think that these areas actually produce conscious representations of object distance, since it could be that they merely support the ability of some other brain area to do so (Chalmers 2000; see also discussion of V1 and MT in 5.3). The second thing needed is reason to think that V3A and/or V7 are involved in the (direct) guidance of motor action. That the studies just discussed do not imply this is something that Wu himself points out, perhaps because-as seen above - the relevant evidence indicates that it is representations of IPS/SPL that feed directly into motor action. Nonetheless, the advocate of EBC should note that V3A and V7 look among the more promising candidates for possibly producing conscious, efficacious representations. ${ }^{25}$

\footnotetext{
${ }^{24}$ Putting it another way, while IPL might be some kind of 'neural correlate of consciousness' (a term coined by Crick and Koch [1990]), it is not what Chalmers would refer to as a content neural correlate of consciousness, 'a minimal neural representational system...such that representation of a content in [it] is sufficient... [given certain background conditions] for representation of that content in consciousness' (2000:31).

${ }^{25}$ Prinz (2012, Chap. 6) has argued that dorsal areas are conscious by appealing to the case of SB, who retains some ability to have visually conscious experiences though his ventral stream is badly damaged (Le et al. 2002). But, as the study's authors point out, SB presents 'a completely unique case' (p. 72), one probably best explained as an instance in which normally unconscious dorsal contents have 'become accessible to perceptual awareness' (p. 58). And so not much can be inferred from the case of SB when it comes to whether dorsal areas are conscious in normal subjects.
} 
In summary, while the dorsal stream produces those representations feeding directly into motor action, it is unlikely that these representations are ever conscious. Most notably, lesions to those dorsal areas that directly guide motor action fail to bring about deficits in visual consciousness. But there is even a tentative case to be made for the dorsal stream producing no conscious representations at all. Overall, then, the dorsal stream is not a good candidate for producing the conscious, efficacious representations hypothesized by the advocate of EBC.

\subsection{Early visual areas do not produce the conscious, efficacious representations}

In the case of the two early visual areas, V1 and MT, the representations they produce are probably not processed enough to be ready for direct use in motor action. ${ }^{26}$ In addition, V1 is commonly thought to not produce conscious representations. We look at each area in turn.

The representations in V1 are too elementary for direct use in motor action. V1 constitutes the first stage of cortical visual processing, its job being to construct something along the lines of what Marr referred to as the 'primal sketch' (1982): Information within V1 mostly consists of a 2D representation of the intensity and wavelength of light arriving from each part of the visual field, though some cells here (due to lateral connections) respond to edges, motion, and binocular disparity (Hubel \& Wiesel 1968, 1998). Importantly, V1 is at a level of processing prior to where things like an object's distance, shape, or size are represented - it is even prior to where the visual field has been segmented into objects. But what is required for motor action are robust representations like those just described, ones that represent an object as an object, and represent things like an object's distance, shape, or size. Plausibly, then, V1 is at too early a stage of processing for its representations to be ready for use in visuomotor action.

In any case, $\mathrm{V} 1$ representations are probably not conscious. This is the view of most contemporary visual neuroscientists, and some compelling data support this claim (Rees, Kreiman \& Koch 2002; Prinz 2012, Chap. 2). It has, however, been argued that activity in V1 is crucial for visual consciousness (Pasquale-de Leone \& Walsh 2001; Tong 2003), on the basis of experiments in which visual experience appeared to require the establishing of feedback loops between V1 and a downstream brain area (Bullier 2001; Pasquale-de Leone \& Walsh 2001). But given the copious evidence against V1 being conscious, the role V1 plays here is most naturally interpreted not as one in which it produces conscious representations, but rather in which it enables representations to become conscious elsewhere; namely, in the downstream brain area.

\footnotetext{
${ }^{26}$ That V1 produces DF's experiences of form is the hypothesis for which Wallhagen shows predilection, because 'V1 is more likely to be associated with low-level (i.e., nonconceptual) sensing' (2007:557). The idea here is that, because V1 is at a level of processing at which perceived properties have not yet been brought under concepts, V1 is a good place to locate the inaccessible experiences Wallhagen hypothesizes DF to have. While it is true such processing is pre-conceptual, it is also probably prior to the level at which robust motor representations are produced, as I explain below.
} 
In sum, in the case of $\mathrm{V} 1$, there is reason to think that its representations are neither conscious nor motorically efficacious.

Next we turn to MT (also known as V5), an area believed to specialize in processing motion information (Born \& Bradley 2005). It is also an area a number of researchers have taken to be where conscious motion representations are produced (Zeki 2003; Schenk \& McIntosh 2010; Prinz 2012, Chap. 6; Wu forthcoming), and many studies support this conclusion (see Block 2007:496). Among other things, increased MT activity correlates with the conscious perception of motion (Heeger et al. 1999), and MT lesions ${ }^{27}$ produce deficits in motion experience (Zihl et al. 1983; Walsh et al. 1998). It should be noted, however, that the arguments made in support of MT producing conscious representations have thus far failed to rule out the leading alternative, which is that motion information does not become conscious until it arrives in the ventral stream (Milner \& Goodale 1995/2006, Chap. 8; Goodale \& Milner 2010). Nonetheless, probably our best guess at this time is that MT produces conscious representations of motion.

What is more doubtful is that MT representations are motorically efficacious. Initially, MT representations appear to be candidates for use in visuomotor action, since acting upon an object in motion will require information about its motion. Milner and Goodale, however, have argued that MT should be classified as "an "early" visual area, one that has the same relationship with the two streams as [V1], but which is specialized for motion processing' (1995/2006:219). In support of this picture, Milner and Goodale point out how both MT and V1 have substantial projections to the ventral and dorsal streams (Felleman and Van Essen 1991), and how lesions to MT or V1 result in both perceptual and visuomotor deficits (Zihl et al. 1983; Walsh et al. 1998; Schenk et al. 2005). If Milner and Goodale are right, and MT occupies a similar position in the visual processing hierarchy as does V1, then MT probably does not produce those motion representations used directly in visuomotor action, for the same reason that V1 probably does not: The representations would need further processing before they were ready for use in motor action.

Overall, it looks unlikely that the early visual areas could supply the conscious, efficacious representations hypothesized by the advocate of EBC. In the case of MT, it is a poor candidate for producing efficacious representations; in the case of V1, it is a poor candidate for producing efficacious or conscious representations. It should be acknowledged that the case against MT producing conscious, efficacious motion representations is not decisive: The idea that MT is properly classified as an early visual area is newer and therefore not yet widely accepted, so it might be hasty — at this point - to conclude that MT does not produce conscious, efficacious representations of motion. But even if it did, this offers only the most limited kind of

\footnotetext{
${ }^{27}$ I use 'lesion' loosely here, so that it refers both to instances of brain damage, and to the 'temporary lesions' induced by transcranial magnetic stimulation, a technique in which brain areas are taken 'offline' with bursts of magnetic energy.
} 
vindication of EBC: Representations of object motion are but one of the many types of representation needed for successful visuomotor action, with representation of things like an object's direction, distance, orientation, and shape also being necessary. But, as seen above, there are probably no representations of these types that are both conscious and efficacious.

In Sect. 3, we saw how advocates of EBC cast doubt on the dissociation argument arguing that there is, within the experience of subjects, content matching the content driving motor action. It was hard to rule out the possibility of such content, in no small part because it is said to be unreportable or otherwise hard to discover. But what we saw in this section is that even if such content exists, it probably does not play a direct role in motor action, since it appears that there are no areas in the visual system producing representations both conscious and efficacious (with caveats in the case of motion).

\section{5: Objections}

In the last section, I presented the neuroanatomical argument against EBC. There are three prominent objections to the argument, each of which I answer in this section.

\subsection{Do newer optic ataxia data show it to involve deficits in consciousness?}

As discussed above, optic ataxia is classically understood as involving only visuomotor deficits. But some newer data suggest optic ataxics might also have perceptual deficits. In a study carried out by Pisella and colleagues (2009; see also 2006), optic ataxics were less accurate than controls at detecting changes in size, position, or orientation of peripherally located stimuli. The advocate of EBC could argue that these results are due to deficits in the ability to consciously perceive peripherally located objects. Were this correct, the Pisella et al. study would act as evidence for optic ataxics having deficits in visual experience, and therefore also as evidence for IPS/SPL producing conscious representations. ${ }^{28}$

However, one would think that if optic ataxics had deficits in conscious perception of object size, position, and/or orientation, there would be a more direct sort of evidence for these deficits, like what is available in achromatopsia (a deficit in conscious color perception; Damasio et al. 1980; Zeki 1990), or akinetopsia (a deficit in conscious motion perception; Zihl et al. 1983). Subjects with these disorders are not merely unable to detect changes in object color or

\footnotetext{
${ }^{28}$ Also relevant, if not as directly so, is a study carried out by Mcintosh and colleagues (2011), in which an optic ataxic (subject IG) was slower than controls in indicating the direction in which a target stimulus had moved. The same observations I make below about the Pisella et al. study could also be made about this study.
} 
motion, they cannot report on object color or motion at all. ${ }^{29}$ But with optic ataxia, there is no similarly direct evidence for subjects having deficits in conscious perception of orientation, position, or size. Perhaps such evidence will appear in the future; pending its appearance, we should prefer whatever other, more plausible explanations are available.

One such explanation is that it is merely attentional deficits causing optic ataxics' inability to detect the changes in the peripherally presented stimuli (Striemer 2007; Pisella et al. 2009; McIntosh et al. 2011). Dorsal areas play an important role in directing visual attention. This is especially true of its inferior areas (e.g., IPL), but other dorsal areas, including IPS/SPL, also participate (Striemer 2007). It is thought that damage to IPS/SPL (and perhaps, to a more limited degree, areas just below IPS/SPL) causes attentional deficits for peripheral parts of the visual field. Plausibly, attentional deficits for the periphery leads to an insensitivity to changes in the periphery, whether there were deficits in consciousness or not. And so perhaps what is preventing optic ataxics from detecting changes in peripherally located stimuli is merely a shortage of attentional resources, and not any purported deficits in visual consciousness. ${ }^{30}$

Overall, the explanation of the Pisella et al. data according to which optic ataxics have conscious deficits should probably be rejected: If there were such deficits, we would expect direct evidence for them (something more direct than an inability to detect a change), but so far there is no such evidence. This provides grounds for preferring the alternative interpretation of these deficits, according to which attentional deficits alone are responsible for optic ataxics' inability to detect the changes. ${ }^{31}$

\subsection{Do optic ataxics have undetected deficits in visual experience?}

Above I presented evidence for IPS/SPL lesions not producing deficits in consciousness. But one might argue that such deficits exist, they are just as yet undiscovered. As discussed above (in 3.1), Mole hypothesizes there to be demonstrative form content within visual experience, content said to be used in motor action, and which is available only when actually performing a motor action. One might be tempted to argue that it is this demonstrative content (or something like it;

\footnotetext{
${ }^{29}$ This could be put more carefully: Since these disorders are often localized to some specific part of the visual field, it will not, strictly speaking, be that they cannot report (e.g.) object color at all, but rather that they cannot report object color in the affected part of the visual field at all.

${ }^{30}$ Note that, in the present explanation, I am not hypothesizing that the peripheral changes are missed because no attention is able to be devoted to the peripherally located object, but rather because there is not enough attention devoted to it. And so the explanation that I am giving here is consistent with the view that attention is necessary for consciousness (Simons \& Chabris 1999; Prinz 2012).

${ }^{31}$ It should be noted that some of the Pisella et al. results act as evidence against IPS/SPL producing conscious shape representations, since optic ataxics performed at the level of controls when asked to detect changes in the shape of peripherally located stimuli.
} 
see Nudds 2007; Schenk \& McIntosh 2010) that is absent from the experience of optic ataxics. Note that this proposal comes with a ready explanation as to why there is thus far no evidence of such deficits: Since such content is fleeting and subtle, perhaps its absence would neither be noticed by the optic ataxic, nor discovered in the course of an examination. And so, the objection concludes, perhaps optic ataxics have deficits in visual experience after all.

If optic ataxia involved deficits in visual experience (even in 'subtle' content), it is probable that there would be evidence - at least anecdotal — of such deficits, given the extent to which optic ataxia has been studied (for review, see Jackson et al. 2009). Still, this consideration falls short of ruling out there to be deficits in the hypothesized subtle content. But even if there were, it is questionable whether they would be relevant to evaluating EBC. I will explain.

Notice that what is key to this objection is the idea that the content in question is, because it is fleeting and subtle, not prominent in one's experience. But remember the original motivation for EBC as a philosophical hypothesis: The rich, detailed representations that we seem to find in visual experience - representations of things like an object's direction, distance, or shape-look well-suited for guiding skilled motor action. Note now that the conscious representations referred to here are prominent within visual experience: Anyone reflecting upon their visual experience easily finds the rich, detailed visual representations that served as inspiration for EBC as a philosophical hypothesis. Likewise, EBC as the commonsense view is plausibly construed as concerning the same prominent features of visual experience.

If so, the present objection might well constitute a change of subject: The content that EBC hypothesizes to be driving motor action is prominent within visual experience, but the content said to be missing from the experience of optic ataxics is subtle; so subtle that even the optic ataxics do not realize that they lost it. And so, even if such content exists, it might not be relevant to evaluating $\mathrm{EBC}$.

\subsection{Should brain lesions be used to determine whether or not a brain area produces conscious representations?}

In 4.2, we saw how IPS/SPL lesions fail to bring about deficits in visual experience, and from this it is was inferred that IPS/SPL probably does not produce conscious representations. However, Chalmers has argued that it is 'methodologically dangerous' to use lesions to determine the location of conscious representations in the brain (2000:32). The problem is that 'lesions change the architecture of the brain, and it is quite possible that changes to brain architecture can change the very location of the [conscious representations]' (2000:29). What Chalmers is worried about here is neuroplasticity, the brain's ability to reorganize its structure in response to damage or experience (Grafman 2000). Because of neuroplasticity, sometimes some

of the function lost because of a lesion is regained by a brain area neighboring the lesion. And so one might claim that conscious deficits have not been observed in conjunction with IPS/SPL 
lesions not because IPS/SPL representations are never conscious, but rather because other parts of the brain take on the job of producing conscious representations if IPS/SPL is disabled.

There are, however, a few reasons to think that the phenomenon of neuroplasticity does not undermine the IPS/SPL lesion data. For one thing, neuroplasticity rarely provides full recovery, and takes a long time when it does (Grafman \& Litvan 1999; Grafman 2000; Frost et al. 2003). This makes it very likely that the optic ataxics would still have had some deficits in visual experience when they were examined, were it the case that IPS/SPL produced conscious representations. But let us look more closely at the scenario that we are considering. In it, the optic ataxics underwent a remarkable recovery in their ability to produce conscious representations, and yet they still suffer from visuomotor deficits (to no small degree). The recovery here appears improbably localized, since it is unlikely that the optic ataxics would have a dramatic recovery in one ability without also having an at least moderate recovery in the other. More importantly, if optic ataxics still have visuomotor deficits, this means they probably have not regained their ability to produce visuomotor representations. But if the optic ataxics regained their conscious representations without regaining their visuomotor representations, the two were probably never the same to start with. It looks, then, as if neuroplasticity does not undermine the IPS/SPL lesion data.

\section{6: Conclusion}

The dissociation argument uses apparent divergences between the contents of visual experience and motor action to argue that visual experience does not play the kind of central role in visuomotor action that we might have pre-theoretically thought. Advocates of EBC have responded by arguing that the dissociations are merely apparent, with the content driving visuomotor action being present within subjects' experiences, just hard to discover. Clark attempted to rule out such content by arguing that it lacks any proper connection to agency, but his argument fell short of showing such content to not exist. I have argued, however, that even if such content does exist, it likely does not directly guide visuomotor action, since current neuroscience fails to support the idea that there are conscious, motorically efficacious visual representations. If this is correct, EBC still faces a compelling empirical threat.

In closing the paper, let us reflect on a strength and a weakness of the neuroanatomical argument against EBC. Recall that EBC has not only a directness clause, but also a typicality clause. There is some evidence available appearing to move EBC closer to having its typicality clause fulfilled. This evidence consists of studies in which motor action appears influenced by content that is conscious and/or of a type usually associated with the ventral stream. ${ }^{32}$ It has been demonstrated, for instance, that the illusory (Franz et al. 2001; Gonzalez et al. 2008) or

\footnotetext{
${ }^{32}$ For reviews of some of the more interesting data, see Schenk \& McIntosh 2010; Sheperd forthcoming.
} 
remembered (McIntosh \& Lashley 2008) size of an object affects motor action under certain circumstances. More intriguingly, some recent experiments suggest that consciously experienced visual illusions can even influence the online control of motor action (Caljouw et al. 2011), a type of motor control usually thought the exclusive province of the dorsal stream (even by critics of dual visual systems theory).

This brings us to a weakness of the neuroanatomical argument: Say there is, in the future, an accumulation of these studies demonstrating correlations between conscious/ventral content and the content driving motor action. This could be used to argue that the typicality clause is satisfied. And, if so, this is nothing that the neuroanatomical argument could gainsay, since it only argues that the consciousness-producing system is distinct from the action-guiding system, but is more or less silent on the question of the frequency or degree to which the former influences the latter.

On the other hand, once it is established that the brain areas directly driving motor action are neuroanatomically distinct from those that are conscious, any number of such correlations between consciousness and motor action cannot help fulfill the directness clause. The problem is that these correlations can be interpreted as instances in which conscious visual information influences motor action only by first being routed through a non-conscious action guiding system. This interpretation, moreover, becomes compulsory with the success of the neuroanatomical argument. And so the strength of the neuroanatomical argument is that it presents a particularly resilient case against the directness clause of EBC being fulfilled.

One issue that we have not had time to look at in this paper is the relative importance of the typicality and directness clauses to EBC. Still, as explained above, we have at least prima facie reason to think that EBC includes a directness clause. It would be notable, then, if there is a good case to be made for it not being fulfilled, something I hope to have done in this paper.

Philosophy Department University of Arizona 


\section{References}

Aglioti, S., DeSouza, J., \& Goodale, M. 1995: Size-contrast illusions deceive the eye but not the hand. Current Biology, 5(6), 679-685.

Campion, J. 1987: Apperceptive agnosia: The specification and description of constructs. In G. Humphreys \& M. Riddoch (eds.), Visual object processing: A cognitive neuropsychological approach, 197-232. London: Erlbaum

Bálint, D. 1909: Seelenlähmung des 'Schauens', optische Ataxie, räumliche Störung der Aufmerksamkeit. pp. 51-66. European Neurology, 25(1), 51-66.

Benson, D. \& Greenberg, J. 1969: Visual form agnosia: A specific defect in visual discrimination. Archives of Neurology, 20(1), 82.

Berryhill, M. E., Fendrich, R., \& Olson, I. R. 2009: Impaired distance perception and size constancy following bilateral occipitoparietal damage. Experimental brain research, 194(3), 381-393.

Binkofski, F., et al. 1999: A parieto-premotor network for object manipulation: evidence from neuroimaging. Experimental Brain Research, 128(1), 210-213.

Block, N. 1995: On a confusion about a function of consciousness. Behavioral and Brain Sciences, 18: 227-87

Block, N. 2007: Consciousness, accessibility, and the mesh between psychology and neuroscience. Behavioral and Brain Sciences, 30(5), 481-498.

Block, N. 2011: Perceptual consciousness overflows cognitive access. Trends in Cognitive Sciences, 15(12), 567-75.

Born, R., \& Bradley, D. 2005: Structure and function of visual area MT. Annu. Rev. Neurosci., 28, 157189.

Brenner, E., \& Smeets, J. B. 1996: Size illusion influences how we lift but not how we grasp an object. Experimental Brain Research, 111(3), 473-476.

Bridge, H., et al. 2013: Structural and functional changes across the visual cortex of a patient with visual form agnosia. The Journal of Neuroscience, 33(31), 12,779-12,791. 
Bridgeman, B., et al. 1979: Relation between cognitive and motor-oriented systems of visual position perception. Journal of Experimental Psychology: Human Perception and Performance, 5, 692700.

Bridgeman, B., Kirsch, M. \& Sperling, A. 1981: Segregation of cognitive and motor aspects of visual function using induced motion. Perception and Psychophysics, 29, 336-42.

Bridgeman, B., Peery, S. \& Anand, S. 1997: Interaction of cognitive and sensorimotor maps of space. Perception and Psychophysics, 59, 456-69.

Briscoe, R. 2009: Egocentric Spatial Representation in Action and Perception. Philosophy and Phenomenological Research, 79(2), 423-460.

Brogaard, B. 2011 a: Conscious vision for action versus unconscious vision for action?. Cognitive science, 35(6), 1076-1104.

Brogaard, B. 2011 b: Are there unconscious perceptual processes?. Consciousness and cognition, 20(2), 449-463.

Brown, R. 2011: The myth of phenomenological overflow. Consciousness and Cognition, 21(2), 599-604.

Bullier, J. 2001: Feedback connections and conscious vision. Trends in Cognitive Sciences, 9, 369-370. Born, R. \& Bradley, D. 2005: Structure and function of visual area MT. Annu. Rev. Neurosci., 28, 157189.

Brenner, E. \& Smeets, J. 1996: Size illusion influences how we lift but not how we grasp an object. Experimental Brain Research, 111(3), 473-476.

Campion, J. 1987: Apperceptive agnosia: The specification and description of constructs. In G. Humphreys \& M. Riddoch (eds.), Visual object processing: A cognitive neuropsychological approach, 197-232. London: Erlbaum

Chalmers, D. 1995: Facing up to the problem of consciousness. Journal of Consciousness Studies, 2(3):200-19.

Chalmers, D. 2000: What is a neural correlate of consciousness? In Metzinger, T. (ed.), Neural Correlates of Consciousness: Empirical and Conceptual Questions. Boston: MIT press.

Cohen, M., \& Dennett, D. 2011: Consciousness cannot be separated from function. Trends in Cognitive Sciences, 15(8), 358-64. 
Culham, J., et al. 2003: Visually guided grasping produces fMRI activation in dorsal but not ventral stream brain areas. Experimental Brain Research, 153(2), 180-189.

Cussins, A. 1998: Nonconceptual Content, Frames of Reference and Trails of Information. Talk presented to the Symposium on Nonconceptual Content, APA, Eastern Division Meeting, Washington D.C., January 1998.

Clark, A. 2001: Visual experience and motor action: Are the bonds too tight? Philosophical Review, 110(4), 495-519.

Clark, A. 2006: Vision as dance? Three challenges for sensorimotor contingency theory. Edinburgh Research Archive. Available at https://www.era.lib.ed.ac.uk/handle/1842/1444

Clark, A. 2007: What reaching teaches: Consciousness, control, and the inner zombie. The British Journal for the Philosophy of Science, 58(3), 563-594.

Clark, A. 2009: Perception, action, and experience: Unraveling the golden braid. Neuropsychologia, 47(6), 1460-1468.

Clark, A., \& Kiverstein, J. 2007: Experience and agency: Slipping the mesh. Behavioral and Brain Sciences, 30(5-6), 502-503.

Committeri, G., et al. 2004: Reference frames for spatial cognition: different brain areas are involved in viewer-, object-, and landmark-centered judgments about object location. Cognitive Neuroscience, Journal of, 16(9), 1517-1535.

Crick, F., \& Koch, C. (1990). Towards a neurobiological theory of consciousness. In Seminars in the Neurosciences, 2, 263-275.

Damasio, A. et al. 1980: Central achromatopsia: Behavioral, anatomic, and physiologic aspects. Neurology, 30(10), 1064-1064.

Damasio, A. \& Damasio, H. 1983: Localization of lesions in achromatopsia and prosopagnosia. Localization in neuropsychology, 331-341.

de Gardelle, V., Sackur, J., \& Kouider, S. 2009: Perceptual illusions in brief visual presentations. Consciousness and cognition, 18(3), 569-577.

Dennett, D. 1995: The Path Not Taken. Behavioral and Brain Sciences. 18, 252-253

Dijkerman, H. C., Milner, A. D., \& Carey, D. P. 1996: The perception and prehension of objects oriented in the depth plane. Experimental Brain Research, 112(3), 442-451. 
Dijkerman, H. C., Milner, A. D., \& Carey, D. P. 1999: Motion parallax enables depth processing for action in a visual form agnosic when binocular vision is unavailable. Neuropsychologia, 37(13), 1505-1510.

Driver, J. \& Vuilleumier, P. 2001: Perceptual awareness and its loss in unilateral neglect and extinction. Cognition, 79, 39-88.

Ellis, R., Flanagan, J., \& Lederman, S. 1999: The influence of visual illusion on grasp position. Experimental Brain Research, 125, 109-14.

Evans, G. 1982: The varieties of reference. Oxford: Clarendon Press.

Efron, R. 1969: What is perception? Boston studies in philosophy of science, 4, 137-173.

Fankhauser, F., \& Kwasniewska, S. 2009: Cortical mechanisms of normal and abnormal processing in the visual system, Part 1: Spatial vision, amblyopia, hyperacuity, modal assumptions: A review. Technology and Health Care, 17(2), 77-97.

Felleman, D. J., \& Van Essen, D. C. 1991: Distributed hierarchical processing in the primate cerebral cortex. Cerebral cortex, 1(1), 1-47.

Franz, V. H., et al. 2001: Effects of visual illusions on grasping. Journal of Experimental Psychology: Human Perception and Performance, 27(5), 1124.

Frost, S., et al. 2003: Reorganization of remote cortical regions after ischemic brain injury: a potential substrate for stroke recovery. Journal of neurophysiology, 89(6), 3205-3214.

Gallese, V. 2007: The 'conscious' dorsal stream: Embodied simulation and its role in space and action conscious awareness. Psyche, 13(1), 1-20.

Garcin, R., Rondot, P. \& De Recondo, J. 1967: Ataxie optique localisée aux deux hémichamps visuels homonymes gauches. Revue de Neurology (Paris), 116, 707-714.

Glover, S. 2003: Optic ataxia as a deficit specific to the on-line control of actions. Neuroscience \& Biobehavioral Reviews, 27(5), 447-456.

Gonzalez, et al. 2008: Practice makes perfect, but only with the right hand: Sensitivity to perceptual illusions with awkward grasps decreases with practice in the right but not in the left hand. Neuropsychologia, 46(2), 624-631. 
Goodale, M. 1998: Visuomotor control: Where does vision end and action begin? Current Biology, 8(14), 489.

Goodale, M., et al. 1991: A neurological dissociation between perceiving objects and grasping them. Nature, 349(6305), 154-156.

Goodale, M., et al. 1994: Separate neural pathways for the visual analysis of object shape in perception and prehension. Current Biology, 4(7), 604-610.

Goodale, M. \& Milner, A. 1992: Separate visual pathways for perception and action. Trends in neurosciences, 15(1), 20-25.

Goodale, M. A., \& Milner, A. D. 2004: Sight Unseen: An Exploration of Conscious and Unconscious Vision. Oxford: Oxford University Press

Goodale, M., Pelisson, D. \& Prablanc, C. 1986: Large adjustments in visually guided reaching do not depend on vision of the hand or perception of target displacement. Nature, 320, 154-6.

Goodale, M. A., \& Milner, A. D. 2004: Sights unseen. Oxford: Oxford University Press

Goodale, M. A., \& Milner, A. D. 2010: Two visual streams: Interconnections do not imply duplication of function. Cognitive Neuroscience, 1(1), 52-62.

Grill-Spector, K., et al. 1998: Cue-invariant activation in object-related areas of the human occipital lobe. Neuron, 21, 191-202.

Grafman, J. 2000: Conceptualizing functional neuroplasticity. Journal of communication disorders, 33(4), 345-356.

Grafman, J., \& Litvan, I. 1999: Evidence for four forms of neuroplasticity. Neuronal plasticity: Building a bridge from the laboratory to the clinic, 131-139.

Gross, C. \& Sergent, J. 1992: Face recognition. Current Opinion in Neurobiology, 2(2), 156-161.

Grush, R. 1998: Skill and spatial content. Electronic Journal of Analytic Philosophy, 6(6).

Haffenden, A. \& Goodale, M. 1998: The effect of pictorial illusion on prehension and perception. Journal of Cognitive Neuroscience, 10(1), 122-136.

Heeger, D., et al. 1999: Motion opponency in visual cortex. The Journal of Neuroscience, 19(16), 71627174. 
Heider, B. 2000: Visual form agnosia: neural mechanisms and anatomical foundations. Neurocase, 6(1), $1-12$.

Hesse, C., Ball, K., \& Schenk, T. 2014: Pointing in Visual Periphery: Is DF's Dorsal Stream Intact? PLOS One, 9(3), e91420.

Himmelbach, M., Boehme, R., \& Karnath, H. O. 2012: 20 years later: A second look on DF's motor behaviour. Neuropsychologia, 50(1), 139-144.

Himmelbach, M. \& Karnath, H. 2005: Dorsal and ventral stream interaction: contributions from optic ataxia. Journal of Cognitive Neuroscience, 17(4), 632-640.

Himmelbach, M., et al. 2009: Brain activation during immediate and delayed reaching in optic ataxia. Neuropsychologia, 47(6), 1508-1517.

Holmes, G. 1918: Disturbances of visual orientation. British Journal of Ophthalmology. 2, 449-506.

Hu, Y., Eagleson, R. \& Goodale, M. 1999: The effects of delay on the kinematics of grasping. Experimental Brain Research, 126(1), 109-116.

Hu, Y. \& Goodale, M. 2000: Grasping after a delay shifts size-scaling from absolute to relative metrics. Journal of Cognitive Neuroscience, 12(5), 856-868.

Hubel, D. \& Wiesel, T. 1968: Receptive fields and functional architecture of monkey striate cortex. The Journal of physiology, 195(1), 215-243.

Hubel, D. \& Wiesel, T. 1998: Early exploration of the visual cortex. Neuron, 20(3), 401-412.

Jacob, P., \& Jeannerod, M. 2003: Ways of Seeing: The Scope and Limits of Visual Cognition. Oxford: Oxford University Press

Jacob, P., \& De Vignemont, F. 2010: Spatial coordinates and phenomenology in the two-visual systems model. In N.Gangopadhyay (ed.), Perception, action, and consciousness: Sensorimotor dynamics and two-visual systems. Oxford: Oxford University Press.

Jackson, S. R., et al. 2009: There may be more to reaching than meets the eye: re-thinking optic ataxia. Neuropsychologia, 47(6), 1397-1408.

James, T., et al. 2003: Ventral occipital lesions impair object recognition but not object-directed grasping: an fMRI study. Brain, 126(11), 2463-2475. 
Kanwisher, N., et al. 1996: Functional imaging of human visual recognition. Cognitive Brain Research; Cognitive Brain Research.

Koch, C., \& Crick, F. 2001: The zombie within. Nature, 411(6840), 893-893.

Kouider, S., de Gardelle, V., \& Dupoux, E. 2007: Partial awareness and the illusion of phenomenal consciousness. Behavioral and Brain Sciences, 30(5-6), 510-511.

Kourtzi, Z. \& Kanwisher, N. 2000: Cortical regions involved in perceiving object shape. The Journal of Neuroscience, 20(9), 3310-3318.

Kourtzi, Z. \& Kanwisher, N. 2001: Representation of perceived object shape by the human lateral occipital complex. Science, 293(5534), 1506-1509.

Kozuch, B. 2014: Prefrontal lesion evidence against higher-order theories of consciousness. Philosophical Studies, 167(3), 721-746.

Króliczak, G., et al. 2006: Dissociation of perception and action unmasked by the hollow-face illusion. Brain Research, 1080(1), 9-16.

Lamme, V. 2006: Towards a true neural stance on consciousness. Trends in Cognitive Sciences. 10(11), 494-501.

Lê, S., et al. 2002: Seeing, since childhood, without ventral stream: a behavioural study. Brain, 125(1), 58-74.

Malach, R., et al. 1995: Object-related activity revealed by functional magnetic resonance imaging in human occipital cortex. Proceedings of the National Academy of Sciences, 92(18), 8135-8139.

Marr, D. 1982: Vision: A computational investigation into the human representation and processing of visual information. Henry Holt and Co: New York

Matthen, M. 2005: Seeing, doing, and knowing: A philosophical theory of sense perception. Oxford: Oxford University Press.

McIntosh, R.D. and Lashley, G. 2008: Matching boxes: Familiar size influences action programming. Neuropsychologia, 46(9), 2441-2444.

McIntosh, R., et al. 2011: Correlated deficits of perception and action in optic ataxia. Neuropsychologia, 49(1), 131-137. 
Milner, A., Dijkerman, H., \& Carey, D. 1999: Visuospatial processing in a pure case of visual-form agnosia. In N. Burgess, J. Jeffery \& J. O'Keefe (eds.) The hippocampal and parietal foundations of spatial cognition, 443-466. Oxford: Oxford University Press.

Milner, A., et al. 1991: Perception and action in 'visual form agnosia'. Brain, 114(1), 405-428.

Milner, A., et al. 2003: Delayed reaching and grasping in patients with optic ataxia. Progress in Brain Research, 142, 225-242.

Milner, A. \& Goodale, M. 1995/2006: The visual brain in action. Oxford: Oxford University Press

Milner, A. \& Goodale, M. 2008: Two visual systems re-viewed. Neuropsychologia, 46(3), 774-785.

Mole, C. 2009: Illusions, Demonstratives, and the Zombie Action Hypothesis. Mind, 118(472), 995-1011.

Mole, C. 2013: Embodied Demonstratives: A Reply to Wu. Mind, 122(485): 231-239.

Moreaud, O. 2003: Balint syndrome. Archives of neurology, 60(9), 1329.

Morel, A. \& Bullier, J. 1990: Anatomical segregation of two cortical visual pathways in the macaque monkey. Visual neuroscience, 4(06), 555-578.

Nagel, T. 1974: What is it like to be a bat? Philosophical Review, 83, 435-50

Nisbett, R. E., \& Wilson, T. D. 1977: Telling more than we can know: Verbal reports on mental processes. Psychological review, 84(3), 231.

Nudds, M. 2007: Seeing how to move: Visually guided action and the 'directive'content of visual experience. Draft manuscript available at: http://homepages. ed. ac. uk/mnudds/papers/shtm. pdf.

O'Regan, J. \& Noë, A. 2001: A sensorimotor account of vision and visual consciousness. Behavioral and brain sciences, 24(5), 939-972.

O'Shaughnessy, B. 1992: The Diversity and Unity of Action and Perception. In T. Crane (ed.), The Contents of Experience. Cambridge: Cambridge University Press.

Pascual-Leone, A. \& Walsh, V. 2001: Fast backprojections from the motion to the primary visual area necessary for visual awareness. Science. 292, 510-12.

Patla, A., \& Goodale, M. 1996: Obstacle avoidance during locomotion is unaffected in a patient with visual form agnosia. NeuroReport, 8(1), 165-168. 
Peacocke, C. 1992: Scenarios, concepts and perception. In T. Crane (ed.), The contents of experience: essays on perception, 105-35. Cambridge: Cambridge University Press.

Perenin M. \& Vighetto, A. 1983: Optic ataxia: a specific disorder in visuomotor coordination. In A. Hein \& Jeannerod, M. (eds.), Spatially Oriented Behavior. New York: Springer.

Perenin M. \& Vighetto, A. 1988: Optic ataxia: A specific disruption in visuomotor mechanisms. Brain, 111(3), 643-674.

Pisella, L., et al. 2006: No double-dissociation between optic ataxia and visual agnosia: Multiple substreams for multiple visuo-manual integrations. Neuropsychologia, 44(13), 2734-2748.

Pisella, L., et al. 2009: Optic ataxia and the function of the dorsal stream: contributions to perception and action. Neuropsychologia. 47, 3033-3044

Prado, J., et al. 2005: Two cortical systems for reaching in central and peripheral vision. Neuron, 48(5), 849-858.

Prinz, J. 2007: Accessed, accessible, and inaccessible: Where to draw the phenomenal line. Behavioral and Brain Sciences, 30, 521-2.

Prinz, J. 2012: The conscious brain. New York: Oxford University Press.

Rees, G., Kreiman, G., \& Koch, C. 2002: Neural correlates of consciousness in humans. Nature Reviews: Neuroscience, 3, 261-70.

Rossetti, Y., et al. 2005: Visually guided reaching: bilateral posterior parietal lesions cause a switch from fast visuomotor to slow cognitive control. Neuropsychologia, 43(2), 162-177.

Sacks, O. 1985: The man who mistook his wife for a hat and other clinical tales. New York: Summit Books

Sheperd, J. (forthcoming): Conscious Control over Action. Mind and Language.

Schneider, G. 1969: Two visual systems: brain mechanisms for localization and discrimination are dissociated by tectal and cortical lesions. Science, 163, 895-902

Schenk, T., et al. 2005: The role of V5/MT+ in the control of catching movements: an rTMS study. Neuropsychologia, 43(2), 189-198.

Schenk, T., \& Milner, A. 2006: Concurrent visuomotor behaviour improves form discrimination in a patient with visual form agnosia. European Journal of Neuroscience, 24(5), 1495-1503. 
Schenk, T., \& McIntosh, R. 2010: Do we have independent visual streams for perception and action? Cognitive Neuroscience, 1(1), 52-62.

Simons, D.J., \& Chabris, C.F. 1999: Gorillas in our midst: Sustained inattentional blindness for dynamic events. Perception, 28, 1059-1074.

Smeets, J. \& Brenner, E. 2001: Action beyond our grasp. Trends in Cognitive Sciences, 5(7), 287-287.

Steeves, J., et al. 2006: The fusiform face area is not sufficient for face recognition: evidence from a patient with dense prosopagnosia and no occipital face area. Neuropsychologia, 44(4), 594-609.

Striemer, C., et al. 2007: Deficits in peripheral visual attention in patients with optic ataxia. Neuroreport, 18(11), 1171-1175.

Tversky, A., \& Kahneman, D. 1983: Extensional versus intuitive reasoning: The conjunction fallacy in probability judgment. Psychological review, 90(4), 293.

Tong, F. 2003: Primary visual cortex and visual awareness. Nature Reviews Neuroscience, 4(3), 219-230.

Ungerleider L. \& Mishkin, M. 1982: Two cortical visual systems. In Ingle, D. et al. (eds.), Analysis of Visual Behavior. Cambridge: MIT Press

Ungerleider, L. \& Haxby, J. 1994: 'What' and 'where' in the human brain. Current opinion in neurobiology, 4(2), 157-165.

Vosgerau, G. \& Newen, A. 2008: Orthogonality of phenomenality and content. American Philosophical Quarterly, 45, 329-348.

Wallhagen, M. 2007: Consciousness and action: Does cognitive science support (mild) epiphenomenalism?. The British Journal for the Philosophy of Science, 58(3), 539-561.

Walsh, V., et al. 1998: Task-specific impairments and enhancements induced by magnetic stimulation of human visual area V5. Proceedings of the Royal Society of London. Series B: Biological Sciences, 265(1395), 537-543.

Wegner, D. M. 2002: The illusion of conscious will. MIT press: Cambridge.

Wong, E. \& Mack, A. 1981: Saccadic programming and perceived location. Acta Psychologica, 48, 12331.

Wu, W. 2013: The Case for Zombie Agency. Mind, 122(485), 217-230. 
Wu, W. (forthcoming): Against Division: Consciousness, Information and the Visual Streams. Mind and Language

Young, M. P. 1992: Objective analysis of the topological organization of the primate cortical visual system. Nature, 358(6382), 152-155.

Zeki, S. 1990: A century of cerebral achromatopsia. Brain, 113(6), 1721-1777.

Zihl, J., Von Cramon, D., \& Mai, N. 1983: Selective disturbance of movement vision after bilateral brain damage. Brain, 106(2), 313-340. 